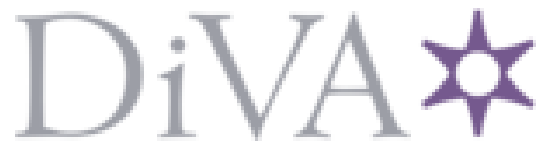

http://www.diva-portal.org

Postprint

This is the accepted version of a paper presented at THE 26TH IAVSD INTERNATIONAL SYMPOSIUM ON DYNAMICS OF VEHICLES ON ROADS AND TRACKS.

Citation for the original published paper:

Casanueva, C., Dirks, B., Tohmmy, B. (2019)

Rail Vehicle Dynamics Simulation-based decision support for novel block brake material implementation in Sweden

In: THE $26^{\text {TH }}$ IAVSD INTERNATIONAL SYMPOSIUM ON DYNAMICS OF VEHICLES ON ROADS AND TRACKS, 12-16 August 2019, Gothenburg, Sweden

N.B. When citing this work, cite the original published paper.

Permanent link to this version:

http://urn.kb.se/resolve?urn=urn:nbn:se:kth:diva-267139 


\title{
Rail Vehicle Dynamics Simulation-based decision support for novel block brake material implementation in Sweden
}

\author{
Carlos Casanueva ${ }^{10000-0003-1583-4625]}$, Babette Dirks ${ }^{2}$ and Tohmmy Bustad ${ }^{2}$ \\ ${ }^{1}$ KTH Royal Institute of Technology, Stockholm, Sweden \\ ${ }^{2}$ Trafikverket - Swedish Transport Administration, Sweden \\ carlosc@kth.se
}

Keywords: TSI Noise, brake block material, UCM, RCF, track damage.

\begin{abstract}
The application of TSI Noise in Sweden needs decision support that can objectively state system-wide benefits and disadvantages, as there are issues with the introduction of novel block brakes: reduced braking performance and increased equivalent conicity. The Roll2Rail Universal Cost Model (UCM) is used to analyse Life Cycle Cost (LCC), as it was also conceived so that it could be used within the decision making processes of infrastructure managers. The simulated characteristics are mainly track Rolling Contact Fatigue (RCF) due to the worsened dynamic train-track interaction.
\end{abstract}

\section{Introduction}

It is nowadays mandatory to substitute cast iron block brakes by novel composite and sintered material block brakes in order to reduce the rolling contact noise. Novel materials generate a smoother wheel surface, reportedly reducing the rolling noise between $3 \mathrm{~dB}$ and $10 \mathrm{~dB}[1]$. However, wear generated in the wheel profile is increased with respect to the cast iron blocks, creating hollow wear and increasing maintenance costs: a suboptimal equivalent conicity leads to increased dynamic forces, increasing damage in wheels, rails, and track substructure. This means that infrastructure managers incur in increased maintenance costs because of a noise-reduction normative. Furthermore, these brakes have shown poor performance regarding safety in Nordic conditions, where the friction coefficient drastically drops with fresh snow below $0^{\circ} \mathrm{C}$, where the snow accumulated in the brake surface creates an effect similar to aquaplaning, reducing the friction coefficient below 0.05 [2]; or the poor thermal conductivity of the novel materials leads to snow melting and posterior freezing of the whole braking system [3], increasing operational risks.

The introduction of silent brakes in Sweden thus needs decision support that can objectively state system-wide benefits and disadvantages. The Roll2Rail Universal Cost Model (UCM) is a good tool for this purpose: it was designed to be able to analyse Life Cycle Costs (LCC) of innovative running gear in order to justify its higher purchase price with the savings in its use phase; it actually serves for analysing any type of discrete change in the running gear. It is also designed so that it can be used within the decision making processes of infrastructure managers, as it can show the impact of discrete changes in the running gear on different stakeholders $[4,5]$. 
In northern Sweden, novel block brakes were introduced in the Iron Ore wagons around year 2010, highlighting the different issues in Nordic conditions. The main objective of this work is to assess the optimality of refurbishing with novel composite or sinter blocks considering the system-wise costs, regarding mainly vehicle, infrastructure, and noise related costs, while also considering safety issues.

\section{Methodology}

The UCM consists of a calculation sheet that converts Key Parameter Indicators (KPI) into costs [6]. The complete UCM framework solves the limitation of not knowing these KPI values by proposing different theoretical models that allow to simulate the different cost-generator KPIs. The UCM is also quite flexible; the user can adapt it to his or her simulation tools and available measurements, making it a very powerful tool when used properly.

The UCM analyses changes by calculating LCC for both an existing vehicle and a modified vehicle, performing simulations for those KPIs that are different between these two cases. In the studied case there some of the cost factors are excluded, as the influence of changing block brake material in these costs is not significant; the only affected costs are:

- Vehicle capital costs: refurbishing of brake systems.

- Vehicle maintenance costs: worn wheel profiles with different reprofiling needs.

- Track maintenance costs: increased rail and track degradation.

- Noise related costs: capital costs (noise shields), comfort costs.

- Potential hazards: accidents due to worsened braking behaviour.

\begin{tabular}{|c|c|c|c|}
\hline Sim. Inputs $\rightarrow$ & Models & KPIs $\rightarrow$ & UCM \\
\hline & & $\begin{array}{l}\text { Measured wheel } \\
\text { wear }\end{array}$ & \multirow{3}{*}{$\begin{array}{l}\text { Maintenance } \\
\text { Wheel reprofiling } \\
\text { Rail grinding }\end{array}$} \\
\hline Track layout & \multirow[b]{2}{*}{$\begin{array}{l}\text { Track Damage } \\
\text { RCF Calculation }\end{array}$} & \multirow[b]{2}{*}{ Predicted rail RCF } & \\
\hline $\begin{array}{c}\text { Vehicle model } \\
\text { Operational data }\end{array}$ & & & \\
\hline $\begin{array}{c}\text { Accident } \\
\text { probablility inputs } \\
\end{array}$ & $\begin{array}{c}\begin{array}{c}\text { Potential } \\
\text { Hazards }\end{array} \\
\end{array}$ & $\begin{array}{c}\text { Accident cost } \\
\text { indicators } \\
\end{array}$ & \multirow[t]{2}{*}{ Operation } \\
\hline & & Sound Pressure level & \\
\hline & & & $\begin{array}{l}\text { Investment } \\
\text { Refurbishing } \\
\text { Noise shields }\end{array}$ \\
\hline
\end{tabular}

Fig. 1. UCM application to the substitution of block brake materials.

Regarding simulations, in order to balance calculation time with the expected results, several damage modes have been disregarded, i.e. wheel RCF and track wear. Figure 1 depicts the setup for the UCM calculations in the project. It will consist on Maintenance, Operation and Investment costs (underlined in Figure 1), and the KPIs that allow for this final cost calculation (bold in Figure 1) are either measured (wheel wear and 
sound pressure level) or simulated (track damage -with Rail Vehicle Dynamics simulations- and potential hazards).

For the comparative cost study, two cases are selected: before the block change and after the change; Trafikverket, the Swedish Transport Administration, provides the necessary data for these calculations: measured worn wheel profiles for both cases, sound pressure levels, investment costs, etc. The differences in track damages are simulated, while track maintenance costs for different years were also provided from Trafikverket as reference.

\subsection{Rail vehicle dynamics model}

The analysed system is the Iron Ore line in northern Sweden. The modelled vehicle is the IORE short-coupled three-piece boogie vehicles with load sensitive frictional damping [7]. Tare wagons weigh 21.6 tons, with a payload of 102 tons. The maximum speed is $70 \mathrm{~km} / \mathrm{h}$ and $60 \mathrm{~km} / \mathrm{h}$ respectively.

It is important to select the right wheel profiles in order to represent the different situations correctly for the UCM. The available wheel profiles (Figure 2) are one worn profile measurement from 2008, before the novel block brake materials were introduced ('old', mileage of ca. $150000 \mathrm{~km}$ ); and two measured profiles from 2014, after the block brake materials had been used for some time ('new1', mileage of ca. $164000 \mathrm{~km}$ and 'new2' with $158000 \mathrm{~km}$ ). The hollow wear pattern caused by the block brakes can clearly be seen in the figure, including the false flange in the field side.

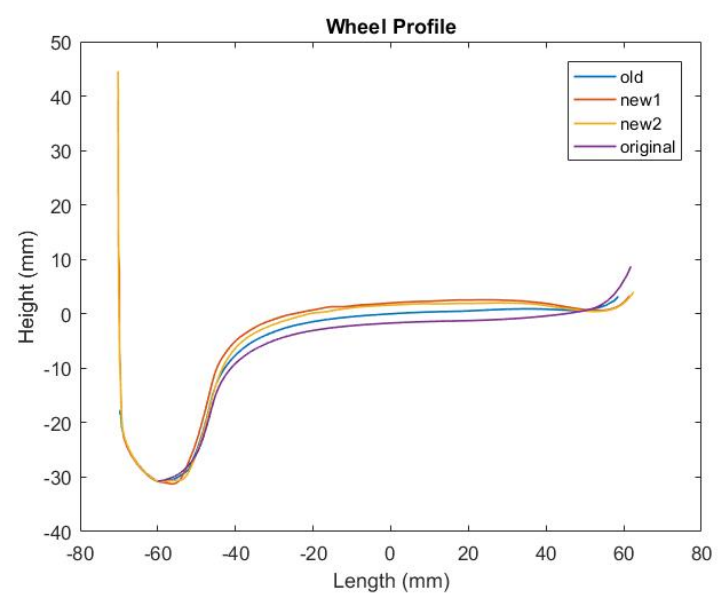

Fig. 2. Wheel profiles used in the MBS: 'original' WP4 profile, 'old' worn profile before the change in block brakes, and 'new' profiles after the change in block brakes.

\subsection{Operational conditions}

For the simulations, the UCM methodology gives specific recommendations to follow. First, a set of characteristic curves was set up in order to represent the actual network 
where the Iron Ore vehicles are running, six curve intervals following the UCM indications. These intervals include curve radius-dependant rail profiles, average gauge, and track irregularities. Additionally, in order to account for the variability in the driving speeds, for curves over $400 \mathrm{~m}$ radius half of the vehicles are considered running with cant deficiency, while over $800 \mathrm{~m}$ radius $1 / 3$ are considered to have cant excess and $1 / 3$ cant deficiency. For straight track and low radius curves no variability is considered. Simulations have also varying friction coefficient as shown in table 1, tailored to climatic conditions in northern Sweden.

Table 1. Variability of wheel-rail friction coefficient

\begin{tabular}{|c|c|}
\hline Proportion & $\boldsymbol{\mu}$ \\
\hline $15 \%$ & 0.25 \\
\hline $50 \%$ & 0.4 \\
\hline $35 \%$ & 0.5 \\
\hline
\end{tabular}

Additionally, there two passenger services per day in the same track. The effect of these services on track damage is ignored due to the major influence of the many trips of heavier freight vehicles.

\subsection{Track damage modelling}

The UCM lists different modelling techniques that can be used for modelling rail wear, RCF and track settlement. As stated before, for this study case only rail RCF will be studied, as it is the driver of maintenance actions in this specific line. The two different options for RCF prediction are the Burstow model [8] and the Dirks model [9]. The UCM requires specific damage KPIs as input in order to perform the costs calculations, and in these two cases these are "mileage to crack initiation" and "crack growth rate" respectively. These are obtained postprocessing Dynamics Simulation results and are manually fed into the UCM file. For simplicity, the Burstow model is selected in this work.

\subsection{Cost modelling}

For this exercise, the intention was to use the UCM as it was delivered in Roll2Rail. There, the user does not need to know anything except the necessary KPIs for the model to work: these KPIs are manually introduced in the UCM, together with some operational characteristics, and the cost for each case is calculated. The tool incorporates default values for all the editable fields, and as the final goal is to calculate differential costs, it is valid to leave the unknown fields as default.

The cost indicators that are modelled are the following:

- Wheel damage: the UCM tool is capable of calculating the reprofiling mileage based on the wear rate of the wheel (KPIs are flange height, thickness and angle for a certain mileage). 
- Track damage: the UCM has a highly complex system for evaluating the direct costs induced from a specific vehicle into the track, and for RCF the main KPI is the crack growth rate.

- Potential hazards: measures the potential catastrophic failures in the components of the running gear, it is represented by a fixed percentage per each running gear type.

- Sound pressure level: there is only one KPI for noise, as the marginal cost is a proportional to the pass-by noise pressure level, in $\mathrm{dB}$.

- Investment in barriers: fixed cost for the instalment of physical noise dampers.

The calculation of these differential costs before and after the change in block brake material will showcase which solution has the best economic impact, regardless of noneconomic needs.

\section{Results and discussion}

This section focuses on the cost indicators most related to Rail Vehicle Dynamics.

\subsection{Wheel damage}

Wheel wear and fatigue is not simulated but taken from measurements. The first issue arises when using only wheel wear for calculating wheel reprofiling costs: the reprofiling distances due to the extrapolated measured wear when applying the EN15313 limits (max. flange height of $36 \mathrm{~mm}$ ) give extremely long running distances before first reprofiling. This occurs because, in reality, wheel wear is not the trigger for wheel reprofiling in this operation, but wheel RCF:

Table 2. Mileage until wheel reprofiling considering only uniform wear

\begin{tabular}{|c|c|c|}
\hline Wheel & Mileage (km) & Trigger \\
\hline Old & 549500 & Flange height $>36 \mathrm{~mm}$ \\
\hline New1 & 272000 & Flange height $>36 \mathrm{~mm}$ \\
\hline New2 & 362000 & Flange height $>36 \mathrm{~mm}$ \\
\hline
\end{tabular}

As previously stated, we were trying to avoid the use of simulations for this section, so reference mileage and crack growth values have been used from previous studies in the same line [7]: wheel reprofiling because of RCF happens after $75000 \mathrm{~km}$ for Old profiles and $100000 \mathrm{~km}$ for New profiles due to the effect of the additional tread wear.

The results (Table 3) show that even if the hollow wear creates higher material removed, the fact that it does not happen that often compensates for this, reducing the actual yearly wheel reprofiling costs for a vehicle.

Table 3. Total estimated costs for wheel reprofiling

\begin{tabular}{|l|l|l|}
\hline & \multicolumn{1}{|c|}{ Old } & \multicolumn{1}{c|}{ New1 } \\
\hline Km between reprofiling (Km) & 74974 & 100130 \\
\hline Material removed (mm) & 4,73 & 6,10 \\
\hline Additional losses (mm) & 2,00 & 2,00 \\
\hline
\end{tabular}




\begin{tabular}{|l|l|l|}
\hline Total reprofiles for yearly operation & 1,80 & 1,35 \\
\hline Total renewals for yearly operation & 0,16 & 0,15 \\
\hline TOTAL COST PER YEAR PER VEHICLE & $\mathbf{3 4 ~ 0 4 7 , 8 6 €}$ & $\mathbf{2 6 ~ 3 6 5 , 6 7} €$ \\
\hline
\end{tabular}

\subsection{Track damage}

For track damage calculations, dynamic simulations were performed in a set of default curve cases. From the combination of operational cases a total of 180 simulations were selected. Figure 3 depicts the number of occurrences during the simulation where the surface fatigue index $F I_{\text {surf }}$ was higher than 1. It is clear that the New profiles with hollow wear decrease the dynamic performance of the vehicles, increasing the occurrence of RCF in a very broad range of curve radiuses.

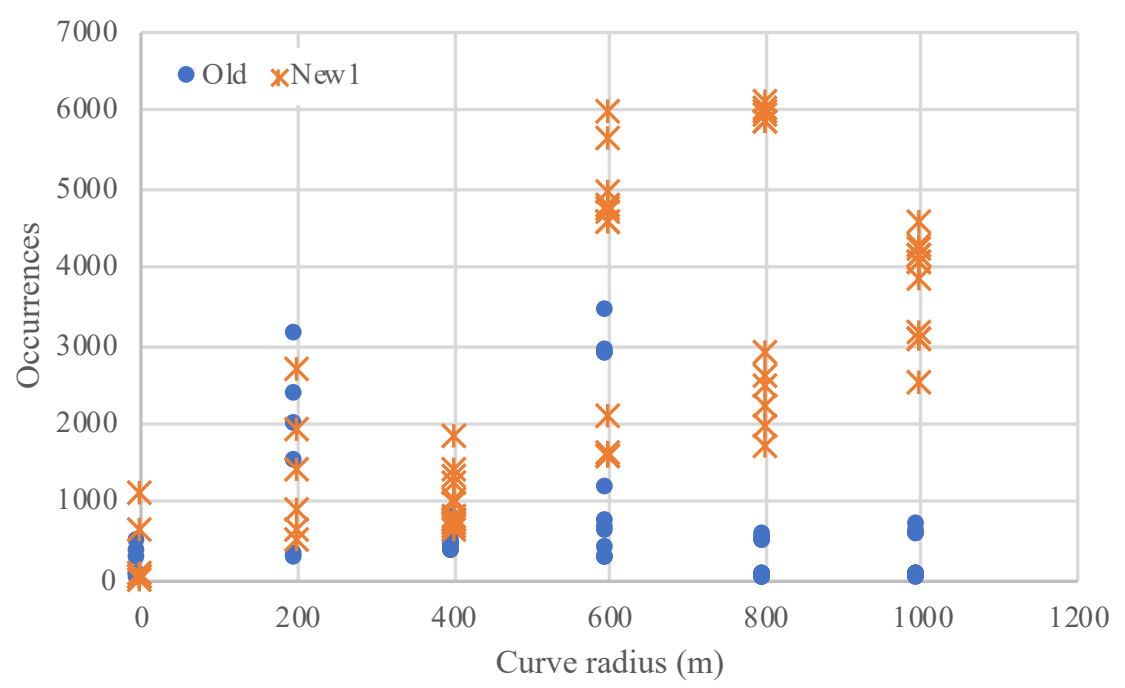

Fig. 3. Number of occurrences $\mathrm{FI}_{\text {surf }}>0$ in each simulation with worn wheel profiles before (Old) and after (New1) change in block brakes. $\mathrm{R}=0 \mathrm{~m}$ represents tangent track.

The second challenge appears at this point, as the RCF KPI is crack growth rate, but one of the recommended modelling techniques in the methodology is the Burstow model, where only crack initiation can be predicted. For the sake of completeness, and given that the performed simulations did not give the needed RCF KPI, crack growth rates from literature and default values from the UCM were used in order to perform an exploratory analysis. Between the Old and New profiles, a 20\% increase in crack growth rate for Newl was implemented. The differential costs are shown in Table 4.

Table 4. Yearly costs, RCF related maintenance, $10 \mathrm{~km}$ section.

\begin{tabular}{|r|c|c|}
\hline & Old & New1 \\
\hline Inspection & $1600 €$ & $1600 €$ \\
\hline
\end{tabular}




\begin{tabular}{|r|r|r|}
\hline Maintenance actions & $2950 €$ & $3040 €$ \\
\hline Infrastructure unavailability & $7422 €$ & $13846 €$ \\
\hline Amortisation of maintenance assets & $413 €$ & $420 €$ \\
\hline Reduction in technical life & $1116 €$ & $1339 €$ \\
\hline Total cost & $\mathbf{1 3 5 0 1} €$ & $\mathbf{2 0 2 4 5} €$ \\
\hline
\end{tabular}

It is worth mentioning that, for the default setup of the UCM, the RCF induced costs are driven by the infrastructure unavailability. The actual differential costs because of reprofiling is almost not affected, as the number of reprofiling actions per year is rounded down. However, the higher crack appearance will increase the probability that these maintenance actions affect traffic outside the maintenance windows, thus heavily penalizing the final cost.

\section{Conclusions and further work}

This work presents the initial stages to calculate the differential LCC of the introduction of composite block brakes in the Iron Ore line in Northern Sweden using the Universal Cost Model developed in Roll2Rail.

The actual vehicle dynamic simulations needed for the calculation of the wheel and track damage KPIs are quite straightforward, with already validated models proposed for its simulation within the UCM framework. However, inconsistencies have been found regarding RCF, where a model is proposed for the simulation of track RCF that does not allow to obtain the KPI needed for cost calculations, crack growth rate.

Additionally, the description of the methodology in the Roll2Rail documents is not straightforward at all, with complex language and shortcuts in the definition of equations that don't allow for its niche usage outside research areas of the vehicle manufacturing industry. Deepening into the UCM, specially the track damage section, showcases its lack of user-friendliness, including but not limited to the huge amount of economic and operational data needed for maintenance cost calculation.

It is difficult to trust the UCM tool when the explanations of what each KPI represents are not clearly stated even in the manual provided with the tool. One has to deal with successive trial and error operations until acceptable understanding of what the tool does, while contradictory results arise in this process, further undermining the trust in the black box that performs cost calculations.

This study intended to serve as a demonstration of the power and flexibility of the UCM, showcasing its possibilities and allowing Trafikverket to take meaningful decisions regarding the implementation of the TSI Noise when considering the particularities of its implementation in Nordic operational conditions. However, it became a demonstration of the lack of user friendliness of the UCM and associated documents, and it did not allow deepening the understanding of what is the necessary precision level for the Rail Vehicle Dynamics simulation models to provide significant cost results, as initially intended.

The development of the UCM continues within different Shift2Rail projects, where this work will add insight to the needs of a fully functional UCM. 


\section{References}

1. B 126.13 E: Synthesis paper on the EuropeTrain operation with LL brake blocks - Final Report. (2013).

2. Olofsson, U., Sundh, J., Bik, U., Nilsson, R.: The influence of snow on the tread braking performance of a train: A pin-on-disc simulation performed in a climate chamber. Proceedings of the Institution of Mechanical Engineers, Part F: Journal of Rail and Rapid Transit. 230, 1521-1530 (2016). https://doi.org/10.1177/0954409715616425.

3. Maria Fahlén: Safety problems with composite brake blocks, https://utk.gov.pl/download/1/40840/SafetyAlertRegardingcompositebrakeblocks.pdf, (2017).

4. Casanueva, C., Dirks, B., Berg, M., Bustad, T.: Track damage prediction for Universal Cost Model applications. In: Proceedings of the 25th IAVSD Symposium on Dynamics of Vehicles on Roads and Tracks., Rockhampton, Australia (2017).

5. Dirks, B., Casanueva, C., Berg, M., Bustad, T.: Wheel damage prediction for Universal Cost Model applications. In: Proceedings of the 25th IAVSD Symposium on Dynamics of Vehicles on Roads and Tracks., Rockhampton, Australia (2017).

6. Melendez, J.: Roll2Rail D4.3: Cost model Methodology. (2017).

7. Hossein Nia, S., Jönsson, P.-A., Stichel, S.: Wheel damage on the Swedish iron ore line investigated via multibody simulation. JRRT. 228, 652-662 (2014). https://doi.org/10.1177/0954409714523264.

8. Burstow, M.: Whole life rail model application and development for RSSB - continued development of an RCF damage parameter. AEA Technology Rail (2004).

9. Dirks, B., Enblom, R., Ekberg, A., Berg, M.: The development of a crack propagation model for railway wheels and rails. Fatigue Fract Engng Mater Struct. 38, 1478-1491 (2015). https://doi.org/10.1111/ffe.12318. 